6-26-2015

\title{
Aerobic Copper-Catalyzed O-Methylation with Methylboronic Acid
}

Clare E. Jacobson

Noella Martinez-Muñoz

David J. Gorin

Smith College, dgorin@smith.edu

Follow this and additional works at: https://scholarworks.smith.edu/chm_facpubs

Part of the Chemistry Commons

\section{Recommended Citation}

Jacobson, Clare E.; Martinez-Muñoz, Noella; and Gorin, David J., "Aerobic Copper-Catalyzed O-Methylation with Methylboronic Acid" (2015). Chemistry: Faculty Publications, Smith College, Northampton, MA.

https://scholarworks.smith.edu/chm_facpubs/7 


\section{Aerobic Copper-Catalyzed O-Methylation with Methylboronic Acid}

Clare E. Jacobson, Noelia Martinez-Muñoz, and David J. Gorin*

Department of Chemistry, Smith College, Northampton, MA 01063

dgorin@smith.edu

Abstract:

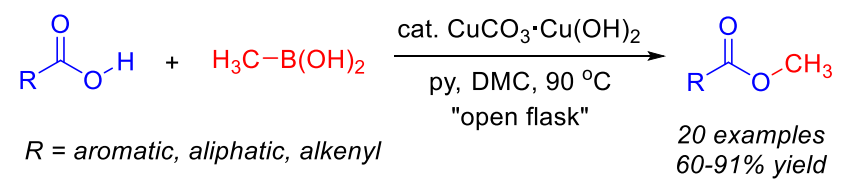

The oxidative coupling of alkylboronic acids with oxygen nucleophiles offers a strategy for replacing toxic, electrophilic alkylating reagents. Although the Chan-Lam reaction is widely applied in the arylation of heteroatom nucleophiles, O-alkylation with boronic acids is rare. We report a Cu-catalyzed nondecarboxylative methylation of carboxylic acids with methylboronic acid that proceeds under air with no additional oxidant. An isotope-labeling study supports an oxidative cross-coupling mechanism, in analogy to that proposed for Chan-Lam arylation. 
The methylation of oxygen nucleophiles is ubiquitous in contemporary academic and industrial organic synthesis. ${ }^{1}$ Typical methods use electrophilic reagents such as methyl iodide, dimethyl sulfate, and diazomethane. ${ }^{2}$ While effective, these reagents are generally unstable and/or hazardous. ${ }^{3}$ which has motivated chemists to seek safer alternatives. as in the use of trimethylsilyl diazomethane rather than diazomethane. ${ }^{4}$ Unfortunately, trimethylsilyl diazomethane exposure is implicated in two recent laboratory-related deaths, ${ }^{5}$ demonstrating the unmet need for safe, effective methylating reagents.

Therefore, we are pursuing alternate strategies and reagents for O-alkylation. ${ }^{6}$ The use of a nucleophilic methyl source to replace typical reagents would avoid the intrinsic toxicity associated with electrophiles, offering a practical advantage. ${ }^{7}$ Additionally, the selective oxidative cross-coupling of an alkylmetal(loid) reagent and an oxygen nucleophile might enable reaction selectivity and functional group compatibility that complement traditional methods. ${ }^{8}$

The Cu-catalyzed oxidative coupling of heteroatom nucleophiles with arylboronic acids, known as the Chan-Lam reaction, is widely-applied for $\mathrm{N}$ - and $\mathrm{O}$-arylation. ${ }^{9}$ In some cases, oxygen present under "open flask" conditions enables catalyst turnover, offering practical and green oxidative conditions. ${ }^{10}$ Despite the success of Chan-Lam arylation, the first couplings of alkylboronic acids with heteroatom nucleophiles have emerged only recently. ${ }^{11}$ Although stoichiometric $\mathrm{Cu}$ is often required, ${ }^{11 \mathrm{~b}-\mathrm{d}, \mathrm{g}}$ the alkylation of phenols, anilines, and amides proceeds with catalytic $\mathrm{Cu}$ using an organic peroxide as the terminal oxidant. ${ }^{11, f}$ To the best of our knowledge, Tsuritani's N-cyclopropylation of indoles is the sole Chan-Lam alkylation that proceeds with catalytic $\mathrm{Cu}$ and air as the only added oxidant. ${ }^{11 a}$

Methylboronic acid (1) and related compounds, especially trimethylboroxine and methyltrifluoroborate salts, have been previously employed as methylating reagents. ${ }^{12}$ Methyl transfer from 1 to canonical nucleophiles is rare; Cruces used stoichiometric $\mathrm{Cu}$ to mediate the $\mathrm{N}$-methylation of anilines, ${ }^{11 \mathrm{c}}$ but this has not yet been extended to any oxygen nucleophile.

Although an array of oxygen nucleophiles participate in Chan-Lam coupling, most examples use phenols or aliphatic alcohols and carboxylic acids are rarely employed. The use of carboxylic acids is complicated by the potential for decarboxylation, which occurs under an array of conditions. ${ }^{13}$ Non-decarboxylative arylations and alkenylations of carboxylic acids with boronic acids are reported, but the analogous 
alkylation has not been demonstrated. ${ }^{14}$ We therefore chose to investigate the synthesis of methyl esters by cross-coupling of 1 and carboxylic acids. ${ }^{15}$

We report herein an aerobic, Cu-catalyzed methylation of carboxylic acids with 1 . The basic reaction conditions complement those of Fisher esterification and the reaction proceeds open to air without any additional oxidant. Mechanistic studies support a Chan-Lam-type mechanism where the methyl group is transferred from the boronic acid to the substrate.

\section{Table 1. Optimization of Cu-Catalyzed Esterification}

\begin{tabular}{|c|c|c|c|c|}
\hline entry $^{a}$ & {$[\mathrm{Cu}]$} & $\begin{array}{l}-\mathrm{B}(\mathrm{OH})_{2} \\
\frac{1}{\text { en flask" }} \\
\text { additive }\end{array}$ & solvent & $\begin{array}{l}3 a \\
\text { yield }(\%)^{b}\end{array}$ \\
\hline $1^{c}$ & $\mathrm{Cu}(\mathrm{OTf})_{2}$ & urea & EtOAc & $<1$ \\
\hline 2 & $\mathrm{Cu}(\mathrm{OAc})_{2}$ & py & dioxane & 54 \\
\hline 3 & $\mathrm{Cu}(\mathrm{OAc})_{2}$ & py & $\mathrm{Cl}-\mathrm{C}_{6} \mathrm{H}_{5}$ & 64 \\
\hline 4 & $\mathrm{Cu}(\mathrm{OAc})_{2}$ & py & DEC & 71 \\
\hline 5 & $\mathrm{CuBr}_{2}$ & py & DEC & $<1$ \\
\hline 6 & $\mathrm{Cu}(\mathrm{OTf})_{2}$ & py & DEC & 47 \\
\hline 7 & $\mathrm{Cu}(\mathrm{acac})_{2}$ & py & DEC & 46 \\
\hline 8 & $\mathrm{CuCO}_{3} \cdot \mathrm{Cu}(\mathrm{OH})_{2}{ }^{d}$ & py & DEC & 73 \\
\hline 9 & $\mathrm{CuCO}_{3} \cdot \mathrm{Cu}(\mathrm{OH})_{2}{ }^{d}$ & $\mathrm{Cs}_{2} \mathrm{CO}_{3}$ & DEC & $<1$ \\
\hline 10 & $\mathrm{CuCO}_{3} \cdot \mathrm{Cu}(\mathrm{OH})_{2}{ }^{d}$ & $\mathrm{Et}_{3} \mathrm{~N}$ & DEC & 10 \\
\hline 11 & $\mathrm{CuCO}_{3} \cdot \mathrm{Cu}(\mathrm{OH})_{2}{ }^{d}$ & urea & DEC & 13 \\
\hline 12 & $\mathrm{CuCO}_{3} \cdot \mathrm{Cu}(\mathrm{OH})_{2}{ }^{d}$ & py & DMC & $71(76)^{\mathrm{e}}$ \\
\hline
\end{tabular}

${ }^{a}$ Reaction conditions: $[\mathbf{2 a}]=0.2 \mathrm{M}$ in solvent, 2.5 equiv $\mathbf{1}, 0.2$ equiv [Cu], 3.5 equiv additive, $90{ }^{\circ} \mathrm{C}, 24 \mathrm{~h} .{ }^{b}$ Determined by ${ }^{19} \mathrm{~F}$ NMR against an internal standard. ${ }^{c}$ Temp $=60^{\circ} \mathrm{C} .{ }^{d} 0.1$ equiv e Isolated yield.

The reaction of 4-fluorobenzoic acid (2a) was chosen for preliminary study so that conversion to $\mathbf{3 a}$ could be quantitatively determined by ${ }^{19} \mathrm{~F}$ NMR. Initial screening conditions were adopted from close literature precedent, with the added constraint that only 0.2 equiv of the Cu catalyst was used. The reaction of $\mathbf{2 a}$ and 1 under Cheng's conditions for the arylation of carboxylic acids ${ }^{14 c}$ yielded no product (Table 1, entry 1). In contrast, $3 a$ was formed in $54 \%$ yield using modified conditions from Cruces' methylation of anilines (entry 2). ${ }^{11 c}$ Surprisingly, this initial result demonstrated catalyst turnover under "open flask" conditions.

Other solvents were screened and found to be effective, including chlorobenzene and diethyl carbonate (DEC) (entries 3-4). Dialkyl carbonates have emerged as non-toxic, green solvents, and therefore DEC was chosen for further optimization studies. ${ }^{16}$ 
Since carboxylic acids are substrates in this chemistry, we sought a catalyst precursor without carboxylate ligands. Although $\mathrm{CuBr}_{2}$ was ineffective, $\mathrm{Cu}$ complexes with oxyanionic ligands of varying basicities, including $\mathrm{Cu}(\mathrm{OTf})_{2}$ and $\mathrm{Cu}(\mathrm{acac})_{2}$, catalyzed formation of $\mathbf{3 a}$ (entries 4-8). Ultimately, cupric carbonate $\left[\mathrm{CuCO}_{3} \cdot \mathrm{Cu}(\mathrm{OH})_{2}\right]$ emerged as the optimal Cu source (entry 8$) .{ }^{17}$

Pyridine is essential for the reaction. When $\mathrm{Cs}_{2} \mathrm{CO}_{3}$ replaced pyridine, no 3a was observed (entry 9). Low yields also resulted with triethylamine or urea (entries 10-11). In the final, optimized conditions, dimethyl carbonate (DMC) replaced higher-boiling DEC to ease solvent removal, and $\mathbf{3 a}$ was isolated in $76 \%$ yield (entry 12).

\section{Table 2. Methylation of Aromatic Carboxylic Acids}

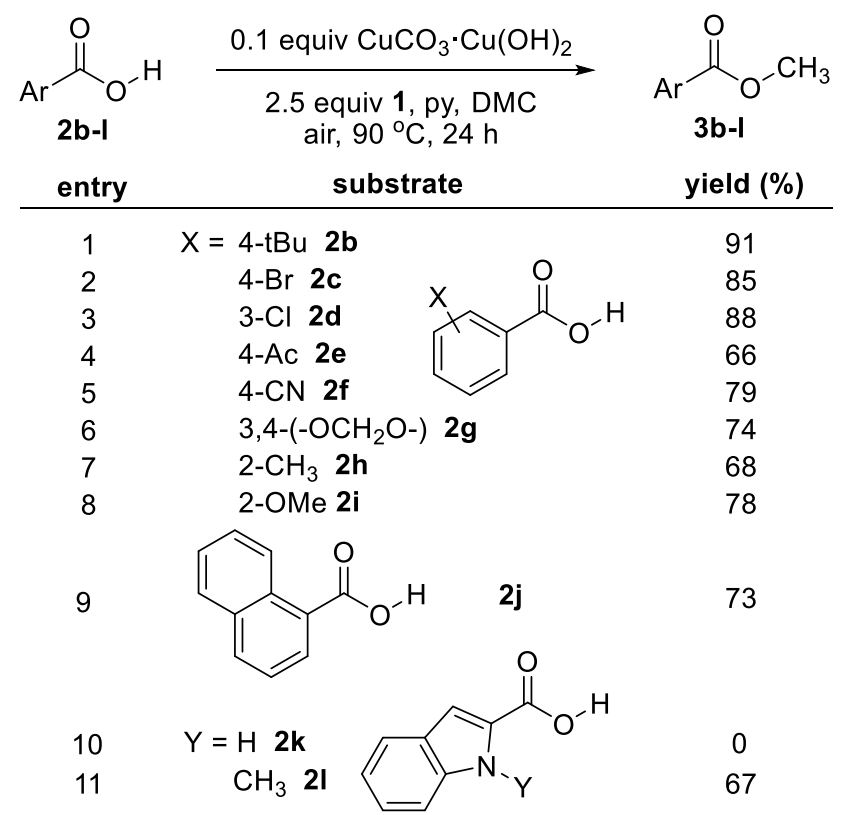

An array of aromatic carboxylic acids undergo Cu-catalyzed oxidative methylation. Alkyl-substituted $\mathbf{2 b}$ provided ester $\mathbf{3 b}$ in $91 \%$ yield. Despite the potential for Cu-mediated reactions of aryl halides, ${ }^{18}$ brominated and chlorinated benzoic acid derivatives were smoothly transformed (entries 2-3). However, no methyl ester was observed in the reaction with 4-iodobenzoic acid.

Electron-deficient substrates with ketone and nitrile substituents formed the corresponding methyl esters 3e and $3 \mathbf{f}$ in $66 \%$ and $79 \%$ yield, respectively (entries $4-5$ ). Electron-donating substituents are similarly tolerated (entries 1, 6-8). For example, piperonylic acid (2g) was methylated in $74 \%$ yield (entry 6$)$.

The methylation of 2-substituted benzoic acid derivatives proceeded despite the increased steric demands of the substrates (entries 7-9). Notably, Pd-catalyzed carboxylate-directed $\mathrm{C}-\mathrm{H}$ methylation of 
$2 \mathrm{~h}$ and similar compounds with $\mathbf{1}$ has been reported. ${ }^{12 b}$ This demonstrates that the chemoselectivity of the methylation event may be controlled by the choice of catalyst and reaction conditions.

Given the importance of aromatic heterocycles, the reaction of indole-2-carboxylic acid (2k) was investigated. Although no product was observed with the $\mathrm{N}-\mathrm{H}$ indole, $\mathrm{N}$-methyl derivative 2l was transformed into $3 \mathbf{l}$ in $67 \%$ yield.

The oxidative methylation was applied to aliphatic carboxylic acids to further probe reaction scope. Hydrocinnamic acid (2m) was methylated in $80 \%$ yield (Table 3, entry 1 ). Neopentylic ester $\mathbf{3 n}$ was also formed, albeit in reduced yield (entry 2). $\alpha$-Oxygenated 20, which might be susceptible to elimination under the basic reaction conditions, provided 30 in $78 \%$ yield (entry 3 ). Substrates with alkene functionality are methylated in moderate yields, including cinnamic acid derivatives (entries 4-6) and primary olefin 2 s (entry 7 ).

\section{Table 3. Esterification of Aliphatic and Alkenyl Substrates}

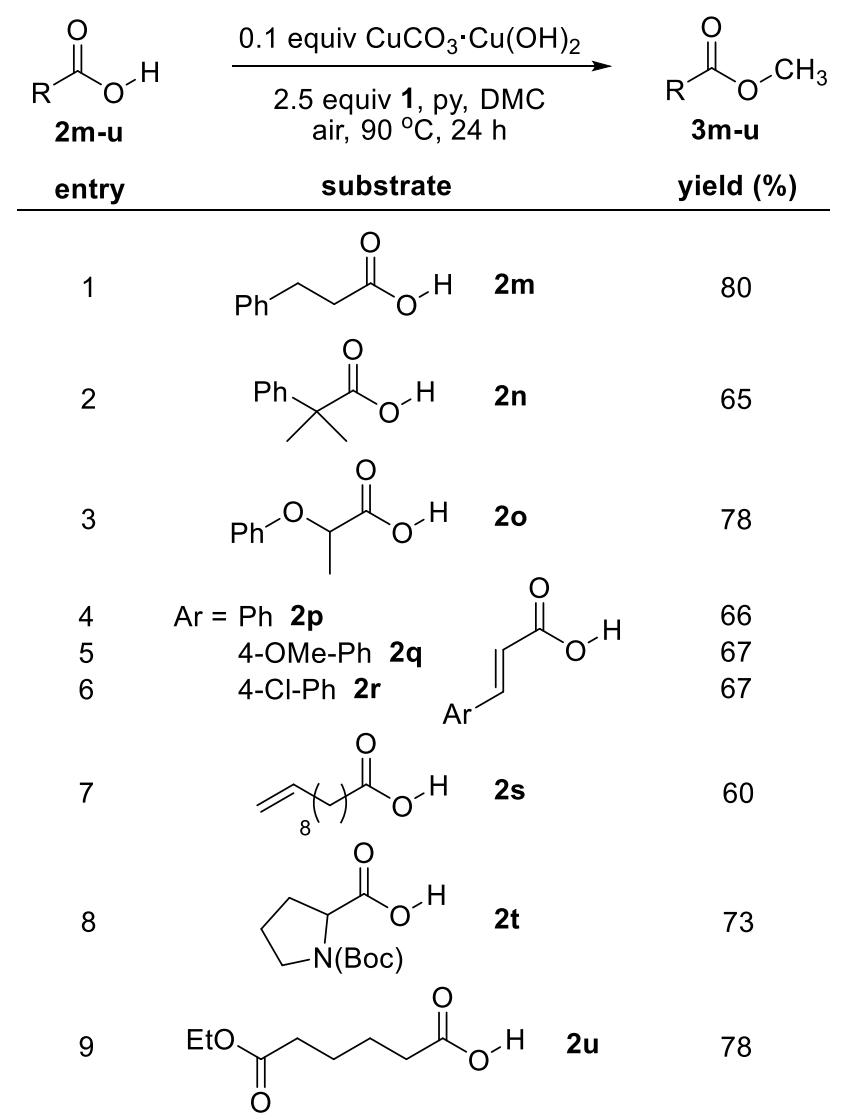

As demonstrated by the transformation of acid-sensitive $\mathrm{N}$-Boc-proline (2t), this O-methylation is complementary to Fisher esterification. Ester $\mathbf{2} \mathbf{u}$ was methylated to see if the ethyl ester would endure. 
Mixed diester $3 \mathbf{u}$ was exclusively observed, demonstrating that transesterification does not occur under the basic reaction conditions.

The coupling of $\mathbf{1}$ with a carboxylic acid requires an oxidation event and we next investigated the terminal oxidant. Since the catalytic reaction proceeds under "open flask" conditions, we propose that molecular oxygen from air serves as the ultimate electron acceptor. To test this, oxygen was excluded from the reaction, which resulted in only trace formation of $\mathbf{3 a}$ (Table 4 , entry 1 ). To exclude the possibility that the combination of atmospheric water and methylboronic acid is the oxidant, ${ }^{19}$ water was added to the reaction. Low product yield was observed, suggesting that oxygen is necessary (entry 2).

Other oxidants were also screened. While use of $\mathrm{HOOtBu}$ and $\mathrm{Phl}(\mathrm{OAc})_{2}$ resulted in low yields, tBuOOtBu provided 3a in yield comparable to the "open-flask" reaction. A control experiment in which $\mathbf{1}$ was omitted resulted in no product formation, suggesting that the peroxide is not the methyl source under these conditions (See SI, eq S1). ${ }^{20}$ While practically the use of air is advantageous, it is noteworthy that the successful reaction observed with tBuOOtBu parallels previous non-aerobic Cu-catalyzed Chan-Lam alkylations. ${ }^{11 e, f}$

\section{Table 4. Terminal Oxidant Screen}

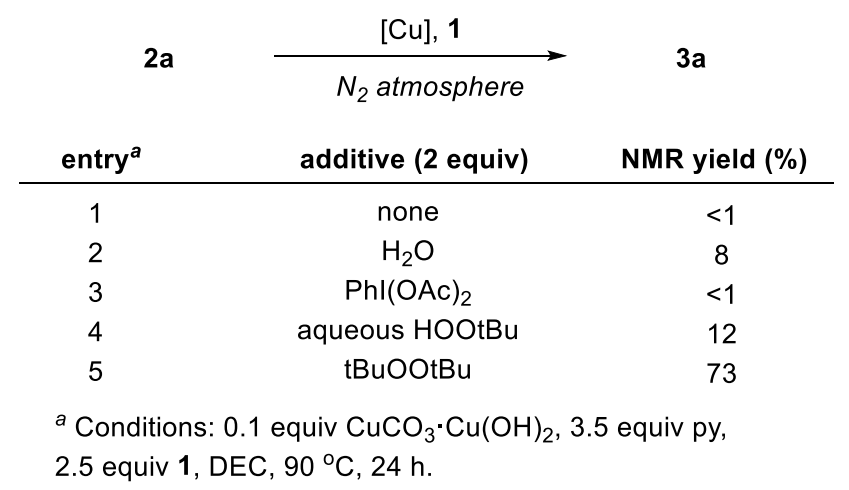

We next considered possible reaction mechanisms. The O-methylation may proceed similarly to ChanLam O-arylation, which has recently been studied (Scheme 1, path A). ${ }^{21}$ In accord with Stahl's studies, intermediate $\mathbf{4}$ may be formed by ligand exchange with the carboxylic acid and transmetallation with 1 . Reductive elimination, likely from a $\mathrm{Cu}(\mathrm{III})$ species, and oxidation with $\mathrm{O}_{2}$ would yield the product and regenerate the $\mathrm{Cu}(\mathrm{II})$ catalyst.

Given the single prior report of aerobic Cu-catalyzed Chan-Lam alkylation, ${ }^{11 a}$ alternate mechanistic pathways were considered. Oxidation of aryl- or alkyl-boronic acids to the corresponding phenols and 
alcohols occurs under a variety of conditions, ${ }^{22}$ and methanol formed in situ might react with the carboxylic acid to form the product (Scheme 1, path B). ${ }^{23}$

\section{Scheme 1. Possible Mechanistic Pathways}

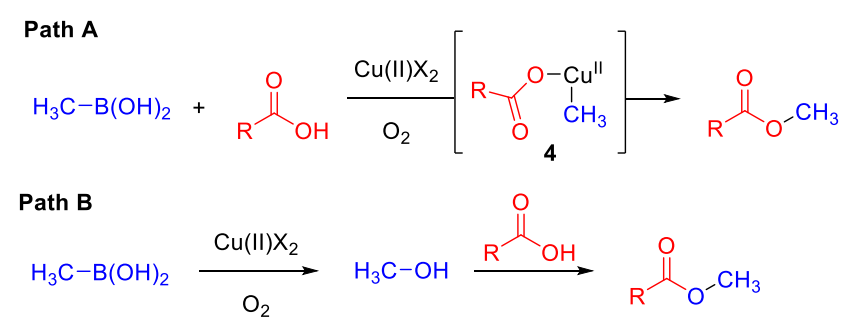

An isotope-labeling experiment was used to differentiate between the mechanistic proposals. The reaction of ${ }^{18} \mathrm{O}$-labeled benzoic acid $\left(\left[{ }^{18} \mathrm{O}\right]_{2}-2 \mathbf{v}\right)$ resulted in the formation of ester $\left[{ }^{18} \mathrm{O}\right]_{2}-\mathbf{3 v}$ with both labeled atoms retained (eq 1). This is inconsistent with a carbonyl substitution mechanism (path B). Additionally, no product was observed upon substitution of methanol for 1 (see SI, eq S2). Taken together, these experiments suggest that Cu-catalyzed O-methylation proceeds via a cross-coupling mechanism analogous to that proposed for Chan-Lam arylation (path A). ${ }^{21}$

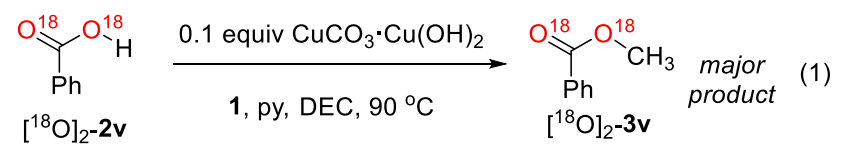

In conclusion, a Cu-catalyzed Chan-Lam methylation of carboxylic acids has been developed. The esterification of aryl, aliphatic, and alkenyl carboxylic acids with 1 proceeds under air without any additional oxidant. The basic reaction conditions complement those of Fisher esterification, and mechanistic studies support a methyl transfer mechanism from 1 to the substrate. This reaction expands the scope of Chan-Lam coupling to include nondecarboxylative alkylation of carboxylic acids and demonstrates a strategy to replace toxic electophilic reagents in O-alkylation.

\section{Experimental Section.}

General Information. Unless otherwise noted, all reagents were obtained commercially and used without further purification. Basic cupric carbonate $\left(\mathrm{CuCO}_{3} \cdot \mathrm{Cu}(\mathrm{OH})_{2}, \mathrm{CAS}: 12069-69-1\right)$ was obtained from Fisher Scientific. TLC analysis of reaction mixtures was performed on silica gel 60 F254 TLC plates using $\mathrm{KMnO}_{4}$ stain and UV light to visualize the reaction components. Column chromatography was carried out 
on $60 \AA, 40-63 \mu \mathrm{m}$ silica gel using mixtures of ethyl acetate and hexanes as eluent. ${ }^{1} \mathrm{H}$ NMR spectra were referenced to chloroform and obtained at a frequency of $300 \mathrm{MHz}$ or $500 \mathrm{MHz}$, as noted. ${ }^{1} \mathrm{H}$-decoupled ${ }^{19} \mathrm{~F}$ NMR spectra were referenced to 4-methoxy-3-nitro-benzotrifluoride and obtained at $470 \mathrm{MHz}$. GCMS analysis was performed using a J\&W DB5-ms GC capillary column $(0.25 \mathrm{~mm} \times 30 \mathrm{~m}, 0.25 \mu \mathrm{M}$ film thickness).

\section{General procedure for optimizing the methylation of $2 a$}

To a 2 dram screw-top vial equipped with a magnetic stir bar was added 2a (31 mg, $0.22 \mathrm{mmol})$, 4methoxy-3-nitro-benzotrifluoride (internal standard, $16 \mathrm{mg}, 0.07 \mathrm{mmol}$ ), and the appropriate solvent $(1.1$ $\mathrm{mL}$ ). The appropriate amine was added (3.5 equiv, $0.77 \mathrm{mmol}$ ). An aliquot (100 uL) was removed and used as the $T=0$ sample for quantifying reaction progress. To the remaining solution was added the copper complex (0.2 equiv, $0.04 \mathrm{mmol}$ ) and methylboronic acid (1) $(30 \mathrm{mg}, 0.5 \mathrm{mmol})$. (For the reactions with $\mathrm{CuCO}_{3} \cdot \mathrm{Cu}(\mathrm{OH})_{2}, 0.1$ equiv of the copper complex was used.) A rubber septa with a vent needle was placed over the top of the screw top vial and the reaction mixture was heated to $90^{\circ} \mathrm{C}$. After stirring for 24 hours, the reaction was cooled and a second aliquot was removed. The $T=0$ and $T=24$ hour aliquots were each diluted in $\mathrm{CDCl}_{3}$ and analyzed by ${ }^{1} \mathrm{H}$-decoupled ${ }^{19} \mathrm{~F}$ NMR.

General procedure for the methylation of carboxylic acids $(2 \mathrm{a}-2 \mathrm{u})$ with 1 . To a $10 \mathrm{~mL}$ round bottom flask equipped with magnetic stir bar and reflux condenser was added the appropriate carboxylic acid (2a-2u, $0.6 \mathrm{mmol}), \mathrm{DMC}(3 \mathrm{~mL}, 0.2 \mathrm{M}$ substrate concentration) and pyridine $(0.17 \mathrm{~mL}, 2.1 \mathrm{mmol})$. Cupric carbonate $\left(\mathrm{CuCO}_{3} \cdot \mathrm{Cu}(\mathrm{OH})_{2}, 13.3 \mathrm{mg}, 0.06 \mathrm{mmol}\right)$ was added, followed by methylboronic acid $(\mathbf{1}, 90 \mathrm{mg}$, $1.5 \mathrm{mmol})$. The heterogenous reaction mixture was left open to ambient air and heated to $90^{\circ} \mathrm{C}$. After 24 hours, the reaction was cooled to room temperature, filtered through celite, and concentrated en vacuo. Pure methyl ester was obtained from the crude residue by flash column chromatography.

Methyl 4-fluorobenzoate (3a, CAS Registry: 403-33-8). Carboxylic acid 2a (84 mg, $0.60 \mathrm{mmol}$ ) was reacted according to the general procedure. After column chromatography (50:1 hexanes/ethyl acetate eluent), methyl ester $\mathbf{3 a}$ was isolated as a clear oil $(70.0 \mathrm{mg}, 76 \%$ yield). The spectral data were 
consistent with reported values. ${ }^{24}{ }^{1} \mathrm{H}$ NMR $\left(\mathrm{CDCl}_{3}, 300 \mathrm{MHz}\right) \delta 8.06(\mathrm{dd}, 2 \mathrm{H}, J=9.0,5.4 \mathrm{~Hz}), 7.11$ (dd, 2 $\mathrm{H}, J=8.7,8.7 \mathrm{~Hz}), 3.91(\mathrm{~s}, 3 \mathrm{H})$.

Methyl 4-tert-butylbenzoate (3b, CAS Registry: 26537-19-9). Carboxylic acid 2b (107 mg, $0.60 \mathrm{mmol})$ was reacted according to the general procedure. After column chromatography (50:1 hexanes/ethyl acetate eluent), methyl ester $\mathbf{3 b}$ was isolated as a clear oil (104.9 $\mathrm{mg}, 91 \%$ yield). The spectral data were consistent with reported values. ${ }^{25}{ }^{1} \mathrm{H}$ NMR $\left(\mathrm{CDCl}_{3}, 300 \mathrm{MHz}\right) \delta 8.00(\mathrm{~d}, 2 \mathrm{H}, J=8.4 \mathrm{~Hz}), 7.47(\mathrm{~d}, 2 \mathrm{H}, J=$ $8.4 \mathrm{~Hz}), 3.92(\mathrm{~s}, 3 \mathrm{H}), 1.36(\mathrm{~s}, 9 \mathrm{H})$.

Methyl 4-bromobenzoate (3c, CAS Registry: 619-42-1). Carboxylic acid 2c (121 mg, $0.60 \mathrm{mmol}$ ) was reacted according to the general procedure. After column chromatography (50:1 hexanes/ethyl acetate eluent), methyl ester 3c was isolated as a white solid (109.7 mg, 85\% yield). The spectral data were consistent with reported values. ${ }^{26}{ }^{1} \mathrm{H}$ NMR $\left(\mathrm{CDCl}_{3}, 300 \mathrm{MHz}\right) \delta 7.88(\mathrm{~d}, 2 \mathrm{H}, J=8.7 \mathrm{~Hz}), 7.56(\mathrm{~d}, 2 \mathrm{H}, J=$ $8.7 \mathrm{~Hz}), 3.90(\mathrm{~s}, 3 \mathrm{H})$.

Methyl 3-chlorobenzoate (3d, CAS Registry: 2905-65-9). Carboxylic acid 2d (94 mg, $0.60 \mathrm{mmol}$ ) was reacted according to the general procedure. After column chromatography (50:1 hexanes/ethyl acetate eluent), methyl ester $\mathbf{3} \mathbf{d}$ was isolated as a clear oil (89.8 $\mathrm{mg}, 88 \%$ yield). The spectral data were consistent with reported values. ${ }^{27}{ }^{1} \mathrm{H}$ NMR $\left(\mathrm{CDCl}_{3}, 300 \mathrm{MHz}\right) \delta 8.02$ (dd, $\left.1 \mathrm{H}, J=1.8,1.8 \mathrm{~Hz}\right), 7.92$ (ddd, $1 \mathrm{H}, J=7.8,1.5,1.5 \mathrm{~Hz}), 7.53$ (ddd, $1 \mathrm{H}, J=8.1,2.1,1.2 \mathrm{~Hz}), 7.38$ (dd, $1 \mathrm{H}, J=7.8,7.8 \mathrm{~Hz}), 3.93(\mathrm{~s}, 3$ H).

Methyl 4-acetylbenzoate (3e, CAS Registry: 3609-53-8). Carboxylic acid 2e (98 mg, $0.60 \mathrm{mmol})$ was reacted according to the general procedure. After column chromatography (50:1 hexanes/ethyl acetate eluent), methyl ester $3 \mathrm{c}$ was isolated as a white solid $(70.0 \mathrm{mg}, 66 \%$ yield $)$. The spectral data were consistent with reported values. ${ }^{28}{ }^{1} \mathrm{H}$ NMR $\left(\mathrm{CDCl}_{3}, 300 \mathrm{MHz}\right) \delta 8.10(\mathrm{~d}, 2 \mathrm{H}, J=8.4 \mathrm{~Hz}), 7.99(\mathrm{~d}, 2 \mathrm{H}, J=$ $8.4 \mathrm{~Hz}), 3.94(\mathrm{~s}, 3 \mathrm{H}), 2.63(\mathrm{~s}, 3 \mathrm{H})$. 
Methyl 4-cyanobenzoate (3f, CAS Registry: 1129-35-7). Carboxylic acid $\mathbf{2 f}$ (88 mg, $0.60 \mathrm{mmol}$ ) was reacted according to the general procedure. After column chromatography (19:1 hexanes/ethyl acetate eluent), methyl ester $\mathbf{3 f}$ was isolated as a white solid $(76.3 \mathrm{mg}, 79 \%$ yield). The spectral data were consistent with reported values. ${ }^{29}{ }^{1} \mathrm{H}$ NMR $\left(\mathrm{CDCl}_{3}, 300 \mathrm{MHz}\right) \delta 8.13(\mathrm{~d}, 2 \mathrm{H}, J=8.7 \mathrm{~Hz}), 7.74(\mathrm{~d}, 2 \mathrm{H}, J=$ $8.7 \mathrm{~Hz}), 3.95(\mathrm{~s}, 3 \mathrm{H})$.

Methyl piperonylate (3g, CAS Registry: 326-56-7). Carboxylic acid $\mathbf{2 g}$ (100 mg, $0.60 \mathrm{mmol})$ was reacted according to the general procedure. After column chromatography (19:1 hexanes/ethyl acetate eluent), methyl ester $\mathbf{3 g}$ was isolated as a white solid $(80.4 \mathrm{mg}, 74 \%$ yield). The spectral data were consistent with reported values. ${ }^{30}{ }^{1} \mathrm{H} \mathrm{NMR}\left(\mathrm{CDCl}_{3}, 300 \mathrm{MHz}\right) \delta 7.65(\mathrm{dd}, 1 \mathrm{H}, J=8.1,1.5 \mathrm{~Hz}), 7.47(\mathrm{~d}, 1 \mathrm{H}, J=1.8 \mathrm{~Hz})$, $6.83(\mathrm{~d}, 1 \mathrm{H}, J=8.1 \mathrm{~Hz}), 6.04(\mathrm{~s}, 2 \mathrm{H}), 3.88(\mathrm{~s}, 3 \mathrm{H})$.

Methyl 2-methylbenzoate (3h, CAS Registry: 89-71-4). Carboxylic acid $\mathbf{2 h}$ (82 $\mathrm{mg}, 0.60 \mathrm{mmol}$ ) was reacted according to the general procedure. After column chromatography (50:1 hexanes/ethyl acetate eluent), methyl ester $3 \mathrm{~h}$ was isolated as a clear oil $(61.6 \mathrm{mg}, 68 \%$ yield). The spectral data were consistent with reported values. ${ }^{28}{ }^{1} \mathrm{H}$ NMR $\left(\mathrm{CDCl}_{3}, 300 \mathrm{MHz}\right) \delta 7.93$ (dd, $1 \mathrm{H}, J=8.1,1.2 \mathrm{~Hz}$ ), 7.41 (ddd, $1 \mathrm{H}, J=7.5,7.5,1.5 \mathrm{~Hz}), 7.27(\mathrm{~m}, 2 \mathrm{H}), 3.91(\mathrm{~s}, 3 \mathrm{H}), 2.63(\mathrm{~s}, 3 \mathrm{H})$.

Methyl 2-methyoxybenzoate (3i, CAS Registry: 606-45-1). Carboxylic acid 2i (91 mg, $0.60 \mathrm{mmol}$ ) was reacted according to the general procedure. After column chromatography (19:1 hexanes/ethyl acetate eluent), methyl ester $\mathbf{3 i}$ was isolated as a white solid $(77 \mathrm{mg}, 78 \%$ yield). The spectral data were consistent with reported values. ${ }^{31}{ }^{1} \mathrm{H}$ NMR $\left(\mathrm{CDCl}_{3}, 300 \mathrm{MHz}\right) \delta 7.81(\mathrm{~d}, 1 \mathrm{H}, J=7.9,1.9 \mathrm{~Hz}), 7.50(\mathrm{~m}$, 1H), $7.00(\mathrm{~m}, 2 \mathrm{H}), 3.90(\mathrm{~s}, 3 \mathrm{H}), 3.89(\mathrm{~s}, 3 \mathrm{H})$.

Methyl 1-naphthoate (3j, CAS Registry: 2459-24-7). Carboxylic acid 2j (103 mg, 0.60 mmol) was reacted according to the general procedure. ${ }^{32}$ After column chromatography (50:1 hexanes/ethyl acetate eluent), methyl ester $\mathbf{3 j}$ was isolated as a clear oil $(81.4 \mathrm{mg}, 73 \%$ yield). The spectral data were consistent with reported values. ${ }^{33}{ }^{1} \mathrm{H} \mathrm{NMR}\left(\mathrm{CDCl}_{3}, 300 \mathrm{MHz}\right) \delta 8.98(\mathrm{~d}, 1 \mathrm{H}, J=8.7 \mathrm{~Hz}), 8.22(\mathrm{dd}, 1 \mathrm{H}, J=7.2,1.2 \mathrm{~Hz})$, 
$8.04(\mathrm{~d}, 1 \mathrm{H}, J=8.1 \mathrm{~Hz}), 7.91(\mathrm{~d}, 1 \mathrm{H}, J=8.1 \mathrm{~Hz}), 7.69-7.49(\mathrm{~m}, 3 \mathrm{H}), 4.04(\mathrm{~s}, 3 \mathrm{H})$. Peaks corresponding to methyl 2-napthoate (CAS Registry: $2459-25-8)^{28}$ were also observed: ${ }^{32} \delta 8.66(\mathrm{~s}, 1 \mathrm{H}$ ), $8.11(\mathrm{~m}, 1 \mathrm{H}), 7.98(\mathrm{~m}, 1 \mathrm{H}), 7.90(\mathrm{~m}, 2 \mathrm{H}), 7.69$ - $7.49(\mathrm{~m}, 2 \mathrm{H}), 4.02(\mathrm{~s}, 3 \mathrm{H})$.

Methyl 1-methylindole-2-carboxylate (3I, CAS Registry: 37493-34-8). Carboxylic acid 2I (105 mg, 0.60 mmol) was reacted according to the general procedure. After column chromatography (50:1 hexanes/ethyl acetate eluent), methyl ester 3 I was isolated as a white solid $(76.5 \mathrm{mg}, 67 \%$ yield). The spectral data were consistent with reported values. ${ }^{34}{ }^{1} \mathrm{H}$ NMR $\left(\mathrm{CDCl}_{3}, 300 \mathrm{MHz}\right) \delta 7.72(\mathrm{~d}, 1 \mathrm{H}, J=7.8$ Hz), $7.40(m, 3 \mathrm{H}), 7.20(\mathrm{~m}, 1 \mathrm{H}), 4.11(\mathrm{~s}, 3 \mathrm{H}), 3.96(\mathrm{~s}, 3 \mathrm{H})$.

Methyl 3-phenylpropanoate (3m, CAS Registry: 103-25-3). Carboxylic acid 2m (90 mg, $0.60 \mathrm{mmol})$ was reacted according to the general procedure. After column chromatography (50:1 hexanes/ethyl acetate eluent), methyl ester $3 \mathrm{~m}$ was isolated as a clear oil $(78.7 \mathrm{mg}, 80 \%$ yield). The spectral data were consistent with reported values. ${ }^{35}{ }^{1} \mathrm{H}$ NMR $\left(\mathrm{CDCl}_{3}, 300 \mathrm{MHz}\right) \delta 7.39-7.18(\mathrm{~m}, 5 \mathrm{H}), 3.71(\mathrm{~s}, 3 \mathrm{H}), 3.00(\mathrm{t}$, $2 \mathrm{H}, J=8.1 \mathrm{~Hz}), 2.68(\mathrm{t}, 2 \mathrm{H}, J=8.1 \mathrm{~Hz})$.

2-Methyl-2-phenylpropionate methyl ester (3n, CAS Registry: 57625-74-8). Carboxylic acid 2n (99 mg, $0.60 \mathrm{mmol})$ was reacted according to the general procedure. After column chromatography (100:1 hexanes/ethyl acetate eluent), methyl ester $3 \mathrm{n}$ was isolated as a clear oil $(69.4 \mathrm{mg}, 65 \%$ yield). The spectral data were consistent with reported values. ${ }^{36}{ }^{1} \mathrm{H}$ NMR $\left(\mathrm{CDCl}_{3}, 300 \mathrm{MHz}\right) \delta 7.43-7.25(\mathrm{~m}, 5 \mathrm{H})$, $3.69(\mathrm{~s}, 3 \mathrm{H}), 1.64(\mathrm{~s}, 6 \mathrm{H})$.

Methyl 2-phenoxypropanoate (3o, CAS Registry: 2065-24-9). Carboxylic acid 20 (100 mg, 0.60 mmol) was reacted according to the general procedure. After column chromatography (50:1 hexanes/ethyl acetate eluent), methyl ester $\mathbf{3 0}$ was isolated as a clear oil $(84.6 \mathrm{mg}, 78 \%$ yield). The spectral data were consistent with reported values. ${ }^{37}{ }^{1} \mathrm{H}$ NMR $\left(\mathrm{CDCl}_{3}, 300 \mathrm{MHz}\right) \delta 7.30(\mathrm{~m}, 2 \mathrm{H}), 7.00(\mathrm{t}, 1 \mathrm{H}, J=7.5 \mathrm{~Hz})$, $6.91(\mathrm{~m}, 2 \mathrm{H}), 4.80(\mathrm{q}, 1 \mathrm{H}, J=6.9 \mathrm{~Hz}), 3.77(\mathrm{~s}, 3 \mathrm{H}), 1.65(\mathrm{~d}, 3 \mathrm{H}, J=6.9 \mathrm{~Hz})$. 
Methyl cinnamate (3p, CAS Registry: 103-26-4). Carboxylic acid 2p (89 mg, $0.60 \mathrm{mmol}$ ) was reacted according to the general procedure. After column chromatography (50:1 hexanes/ethyl acetate eluent), methyl ester $3 p$ was isolated as a white solid $(64.1 \mathrm{mg}, 66 \%$ yield $)$. The spectral data were consistent with reported values. ${ }^{28}{ }^{1} \mathrm{H} \mathrm{NMR}\left(\mathrm{CDCl}_{3}, 300 \mathrm{MHz}\right) \delta 7.72(\mathrm{~d}, 1 \mathrm{H}, J=15.9 \mathrm{~Hz}), 7.54(\mathrm{~m}, 2 \mathrm{H}), 7.40(\mathrm{~m}, 3 \mathrm{H})$, $6.47(\mathrm{~d}, 1 \mathrm{H}, J=16.2 \mathrm{~Hz}), 3.83(\mathrm{~s}, 3 \mathrm{H})$.

Methyl 4-methoxycinnamate (3q, CAS Registry: 943-89-5). Carboxylic acid 3q (107mg, 0.60 mmol) was reacted according to the general procedure. After column chromatography (50:1 hexanes/ethyl acetate eluent), methyl ester $\mathbf{3 q}$ was isolated as a white solid $(76.8 \mathrm{mg}, 67 \%$ yield). The spectral data was consistent with reported values. ${ }^{38}{ }^{1} \mathrm{H}$ NMR $\left(\mathrm{CDCl}_{3}, 300 \mathrm{MHz}\right) \delta 7.65(\mathrm{~d}, 1 \mathrm{H}, J=15.9 \mathrm{~Hz}), 7.47(\mathrm{~d}, 2 \mathrm{H}, J$ $=8.6 \mathrm{~Hz}), 6.90(\mathrm{~d}, 2 \mathrm{H}, J=8.8 \mathrm{~Hz}), 6.32(\mathrm{~d}, 1 \mathrm{H}, J=15.9 \mathrm{~Hz}), 3.83(\mathrm{~s}, 3 \mathrm{H}), 3.80(\mathrm{~s}, 3 \mathrm{H})$.

Methyl 4-chlorocinnamate (3r, CAS Registry: 7560-44-3). Carboxylic acid 2r (110 mg, $0.60 \mathrm{mmol})$ was reacted according to the general procedure. After column chromatography (50:1 hexanes/ethyl acetate eluent), methyl ester $3 p$ was isolated as a white solid $(79.6 \mathrm{mg}, 67 \%$ yield). The spectral data were consistent with reported values. ${ }^{39}{ }^{1} \mathrm{H}$ NMR $\left(\mathrm{CDCl}_{3}, 300 \mathrm{MHz}\right) \delta 7.64(\mathrm{~d}, 1 \mathrm{H}, J=16.2 \mathrm{~Hz}), 7.44(\mathrm{~d}, 2 \mathrm{H}, J$ $=8.4 \mathrm{~Hz}), 7.35(\mathrm{~d}, 2 \mathrm{H}, J=8.7 \mathrm{~Hz}), 6.40(\mathrm{~d}, 1 \mathrm{H}, J=15.9 \mathrm{~Hz}), 3.81(\mathrm{~s}, 3 \mathrm{H})$.

Methyl 10-undecenoate (3s, CAS Registry: 111-81-9). Carboxylic acid 2s (110 mg, $0.60 \mathrm{mmol}$ ) was reacted according to the general procedure. After column chromatography (50:1 hexanes/ethyl acetate eluent), methyl ester $3 \mathbf{s}$ was isolated as a clear oil $(70.5 \mathrm{mg}, 60 \%$ yield). The spectral data were consistent with reported values. ${ }^{40}{ }^{1} \mathrm{H}$ NMR $\left(\mathrm{CDCl}_{3}, 300 \mathrm{MHz}\right) \delta 5.80(\mathrm{~m}, 1 \mathrm{H}), 4.95(\mathrm{~m}, 2 \mathrm{H}), 3.66(\mathrm{~s}, 3 \mathrm{H})$, $2.30(\mathrm{t}, 2 \mathrm{H}, J=7.5 \mathrm{~Hz}), 2.03(\mathrm{~m}, 2 \mathrm{H}), 1.62(\mathrm{~m}, 2 \mathrm{H}), 1.29(\mathrm{~m}, 10 \mathrm{H})$.

Boc-Pro-OMe (3t, CAS Registry: 145681-01-2). Carboxylic acid 2t (129 mg, $0.60 \mathrm{mmol}$ ) was reacted according to the general procedure. After column chromatography (10:1 hexanes/ethyl acetate eluent), methyl ester 3t was isolated as a clear oil $(100.1 \mathrm{mg}, 73 \%$ yield). The spectral data were consistent with 
reported values and indicated the presence of conformational isomers. ${ }^{41}{ }^{1} \mathrm{H} \mathrm{NMR}\left(\mathrm{CDCl}_{3}, 300 \mathrm{MHz}\right) \delta$ 4.27 - $4.15(\mathrm{~m}, 1 \mathrm{H}), 3.68(\mathrm{~s}, 3 \mathrm{H}), 3.54-3.30(\mathrm{~m}, 2 \mathrm{H}), 2.28$ - $1.71(\mathrm{~m}, 4 \mathrm{H}), 1.43-1.36(\mathrm{~m}, 9 \mathrm{H})$.

Ethyl methyl adipate (3u, CAS Registry: 18891-13-9). Carboxylic acid 2u (105 mg, 0.60 mmol) was reacted according to the general procedure. After column chromatography (19:1 hexanes/ethyl acetate eluent), methyl ester $3 \mathbf{u}$ was isolated as a clear oil $(88.8 \mathrm{mg}, 78 \%$ yield). The spectral data were consistent with reported values. ${ }^{42}{ }^{1} \mathrm{H} \mathrm{NMR}\left(\mathrm{CDCl}_{3}, 500 \mathrm{MHz}\right) \delta 4.08(2 \mathrm{H}, \mathrm{q}, J=7.0 \mathrm{~Hz}), 3.62(\mathrm{~s}, 3 \mathrm{H})$, $2.28(\mathrm{~m}, 4 \mathrm{H}), 1.62(\mathrm{~m}, 4 \mathrm{H}), 1.21(\mathrm{t}, 3 \mathrm{H}, J=7.0 \mathrm{~Hz})$.

\section{Procedure and GCMS data for the Isotope-Labeling Experiment (eq 1).}

$\left[{ }^{18} \mathrm{O}\right]_{2}-2 \mathbf{v}$ was prepared from benzotrichloride (Acros) and ${ }^{18} \mathrm{O}$-water (97\%, Cambridge Isotope) as previously reported. ${ }^{43}$ The ${ }^{1} \mathrm{H}$ NMR spectral data were consistent with the values observed for $2 \mathbf{v}$. GCMS $m / z$ (\% relative intensity, ion): $126.2(81 \%, M), 107.2\left(100 \%, M-\left({ }^{18} \mathrm{OH}\right)\right), 77.1\left(94 \%, \mathrm{M}-\left(\mathrm{C}\left[{ }^{18} \mathrm{O}\right] 2 \mathrm{H}\right)\right)$. The molecular ion peak corresponding to $\left[{ }^{18} \mathrm{O}\right]-2 \mathrm{v}$ was also identified: $124.1(3.6 \%, \mathrm{M})$. The molecular ion peak corresponding to unlabeled $2 \mathbf{v}$ was also identified: $122.1(1.3 \%, M)$. The percentage of ${ }^{18} \mathrm{O}$ in synthetic $\left[{ }^{18} \mathrm{O}\right]_{2}-2 \mathrm{v}$ was therefore calculated to be $96.5 \%$.

$\left[{ }^{18} \mathrm{O}\right]_{2}-2 \mathbf{v}$ was reacted with $\mathbf{1}$ according to the general methylation procedure. An aliquot was taken from the reaction at $\mathrm{T}=24 \mathrm{~h}$ and analyzed by GCMS. $\left[{ }^{18} \mathrm{O}\right]_{2}-3 \mathbf{v}$ was identified. GCMS $m / z$ (\% relative intensity, ion): $140.2(28.8 \%, M), 107.2\left(100 \%, M-\left({ }^{18} \mathrm{OCH}_{3}\right)\right)$. The molecular ion peak corresponding to $\left[{ }^{18} \mathrm{O}\right]-3 \mathbf{v}$ was also identified: $138.2(10.2 \%, M)$. The molecular ion peak corresponding to unlabeled $\mathbf{3 v}$ was also identified: $136.2(1.2 \%, \mathrm{M})$. The calculated percentages of product formed are $72 \%\left[{ }^{18} \mathrm{O}\right]_{2}-3 \mathbf{v}, 25 \%\left[{ }^{18} \mathrm{O}\right]-$ 3v, and 3\% 3v. A peak for the benzoic acid $\left(\left[{ }^{18} \mathrm{O}\right]_{2} 2 \mathbf{v}\right)$ was also observed. $m / z$ (\% relative intensity, ion): $126.2(71.8 \%, \mathrm{M}), 107.2\left(100 \%, \mathrm{M}-\left({ }^{18} \mathrm{OCH}_{3}\right)\right)$. The molecular ion peak corresponding to $\left[{ }^{18} \mathrm{O}\right]-2 \mathrm{v}$ was also identified: $124.2(28.5 \%, M)$. The molecular ion peak corresponding to unlabeled $2 \mathbf{v}$ was also identified: $122.2(12.6 \%, M)$. The calculated percentages of $\mathbf{2 v}$ epitopes are $64 \%\left[{ }^{18} \mathrm{O}\right]_{2}-\mathbf{2 v}, 25 \%\left[{ }^{18} \mathrm{O}\right]-\mathbf{2 v}$, and $11 \% \mathbf{2 v}$. 
Acknowledgment We gratefully acknowledge financial support from the donors of the American Chemical Society Petroleum Research Fund (\#52706-UNI1) and Smith College for a Jean Picker Fellowship (DG) and a McKinley Fellowship (NM). We thank Dr. Charles Amass (Smith College) for assistance with instrumentation and Dr. Craig F. Gorin (Dow) for helpful discussions.

Supporting Information Available Control experiments with tBuOOtBu (eq S1) and $\mathrm{MeOH}$ (eq S2). Copies of ${ }^{1} \mathrm{H}$ NMR spectra for $3 \mathbf{a}-3 \mathbf{u}$. This material is available free of charge via the Internet at http://pubs.acs.org.

\section{References:}

(1) Recent examples in natural product synthesis: a) Deng, J.; Zhou, S.; Zhang, W.; Li, J.; Li, R.; Li, A. J. Am. Chem. Soc. 2014, 136, 8185. b) Qin, T.; Porco, J. A. Angew. Chem. Int. Ed. 2014, 53, 3107. In reaction development: c) Mita, T.; Higuchi, Y.; Sato, Y. Org. Lett. 2014, 16, 14. d) Neufeld, K.; Henßen, B.; Pietruszka, J. Angew. Chem. Int. Ed. 2014, 53, 13253. In medicinal chemistry: e) Deng, Y.; Shipps, G. W.; Cooper, A.; English, J. M.; Annis, D. A.; Carr, D.; Nan, Y.; Wang, T.; Zhu, H. Y.; Chuang, C.-C.; Dayananth, P.; Hruza, A. W.; Xiao, L.; Jin, W.; Kirschmeier, P.; Windsor, W. T.; Samatar, A. A. J. Med. Chem. 2014, 57, 8817. f) Zheng, P.; Somersan-Karakaya, S.; Lu, S.; Roberts, J.; Pingle, M.; Warrier, T.; Little, D.; Guo, X.; Brickner, S. J.; Nathan, C. F.; Gold, B.; Liu, G. J. Med. Chem. 2014, 57, 3755.

(2) For a review, see: Lamoureux, G.; Aguero, C. ARKIVOC 2009, 251.

(3) a) Hite, M.; Rinehart, W.; Braun, W.; Peck, H. Am. Ind. Hyg. Assoc. J. 1979, 40, 600. b) Rippey, J. C. R.; Stallwood, M. I. Emerg. Med. J. 2005, 22, 878. c) Mileson, B. E.; Sweeney, L. M.; Gargas, M. L.; Kinzell, J. Inhal. Toxicol. 2009, 21, 583.

(4) a) Hodnett, N. S. Synlett 2003, 2095. b) de Boer, T. J.; Backer, H. J. Org. Synth. 1956, 4, 16.

(5) Kemsley, J. N. Chem. Eng. News 2011, 89, 15.

(6) Ji, Y.; Sweeney, J.; Zoglio, J.; Gorin, D. J. J. Org. Chem. 2013, 78, 11606.

(7) (a) Schwöbel, J. A. H.; Koleva, Y. K.; Enoch, S. J.; Bajot, F.; Hewitt, M.; Madden, J. C.; Roberts, D. W.; Schultz, T. W.; Cronin, M. T. D. Chem. Rev. 2011, 111, 2562. (b) Enoch, S. J.; Ellison, C. M.; Schultz, T. W.; Cronin, M. T. D. Crit. Rev. Toxicol. 2011, 41, 783.

(8) For a review of cross-coupling reactions of two nucleophiles, see: Liu, C.; Zhang, H.; Shi, W.; Lei, A. Chem. Rev. 2011, 111, 1780.

(9) For reviews, see: a) Qiao, J.; Lam, P. Synthesis 2011, 2011, 829. b) Allen, S. E.; Walvoord, R. R.; Padilla-Salinas, R.; Kozlowski, M. C. Chem. Rev. 2013, 113, 6234. For recent catalytic, aerobic examples, see: c) Kumar, K. A.; Kannaboina, P.; Dhaked, D. K.; Vishwakarma, R. A.; Bharatam, P. V.; Das, P. Org. Biomol. Chem. 2015, 13, 1481. d) El Khatib, M.; Molander, G. A. Org. Lett. 2014, 16, 4944. e) Liu, C.-Y.; Li, Y.; Ding, J.-Y.; Dong, D.-W.; Han, F.-S. Chem. Eur. J. 2014, 20, 2373. f) Rasheed, S.; Rao, D. N.; Reddy, K. R.; Aravinda, S.; Vishwakarma, R. A.; Das, P. RSC Advances 2014, 4, 4960. (10) Reviews of aerobic metal catalysis: a) Shi, Z.; Zhang, C.; Tang, C.; Jiao, N. Chem. Soc. Rev. 2012, 41, 3381. b) Campbell, A. N.; Stahl, S. S. Acc. Chem. Res. 2012, 45, 851. Also see ref 9b.

(11) Cyclopropylboronic acid: a) Tsuritani, T.; Strotman, N. A.; Yamamoto, Y.; Kawasaki, M.; Yasuda, N.; Mase, T. Org. Lett. 2008, 10, 1653. b) Bénard, S.; Neuville, L.; Zhu, J. Chem. Commun. 2010, 46, 3393. Methylboronic acid: c) González, I.; Mosquera, J.; Guerrero, C.; Rodríguez, R.; Cruces, J. Org. Lett. 2009, 11, 1677. Other alkylboranic acids: d) Larrosa, M.; Guerrero, C.; Rodríguez, R.; Cruces, J. Synlett 2010, 2101. e) Rossi, S. A.; Shimkin, K. W.; Xu, Q.; Mori-Quiroz, L. M.; Watson, D. A. Org. Lett. 2013, 15, 2314. Alkylboronic esters: f) Sueki, S.; Kuninobu, Y. Org. Lett. 2013, 15, 1544. Alkylboranes: g) Naya, L.; Larrosa, M.; Rodríguez, R.; Cruces, J. Tetrahedron Lett. 2012, 53, 769. 
(12) Suzuki-Miyaura coupling: a) Gray, M.; Andrews, I. P.; Hook, D. F.; Kitteringham, J.; Voyle, M. Tetrahedron Lett. 2000, 41, 6237. C-H methylation: b) Giri, R.; Maugel, N.; Li, J.-J.; Wang, D.-H.; Breazzano, S. P.; Saunders, L. B.; Yu, J.-Q. J. Am. Chem. Soc. 2007, 129, 3510. Addition to carbonyl electrophiles: c) Wang, D.; Ge, B.; Ju, A.; Zhou, Y.; Xu, C.; Ding, Y. J. Organomet. Chem. 2015, 780, 30. d) Takatsu, K.; Shintani, R.; Hayashi, T. Angew. Chem. Int. Ed. 2011, 50, 5548. For an overview of the reactivity of alkylboronic acids, see: e) Hall, D. G. In Boronic Acids; Hall, D. G., Ed.; Wiley-VCH Verlag $\mathrm{GmbH} \&$ Co. KGaA, 2011; pp 13-15, 61.

(13) a) Jiang, Y.; Pan, S.; Zhang, Y.; Yu, J.; Liu, H. Eur. J. Org. Chem. 2014, 2014, 2027. b) Bhadra, S.; Dzik, W. I.; Gooßen, L. J. J. Am. Chem. Soc. 2012, 134, 9938. For a review of carboxylic acids in metal catalysis, see: c) Gooßen, L. J.; Rodríguez, N.; Gooßen, K. Angew. Chem. Int. Ed. 2008, 47, 3100.

(14) a) Huang, F.; Quach, T. D.; Batey, R. A. Org. Lett. 2013, 15, 3150. b) Popovic, S.; Bieräugel, H.; Detz, R. J.; Kluwer, A. M.; Koole, J. A. A.; Streefkerk, D. E.; Hiemstra, H.; van Maarseveen, J. H. Chem. Eur. J. 2013, 19, 16934. c) Zhang, L.; Zhang, G.; Zhang, M.; Cheng, J. J. Org. Chem. 2010, 75, 7472. d) Dai, J.-J.; Liu, J.-H.; Luo, D.-F.; Liu, L. Chem. Commun. 2011, 47, 677. e) Luo, F.; Pan, C.; Qian, P.; Cheng, J. Synthesis 2010, 2005.

(15) For a mechanistically distinct esterification with methylboronic acid, see: a) Lu, W.; Chen, J.; Liu, M.; Ding, J.; Gao, W.; Wu, H. Org. Lett. 2011, 13, 6114. For a review of transition-metal catalyzed esterification, see: b) Luo, F.; Pan, C.; Cheng, J. Synlett 2012, 23, 357.

(16) a) Schäffner, B.; Schäffner, F.; Verevkin, S. P.; Börner, A. Chem. Rev. 2010, 110, 4554. b) ACS GCI Pharmaceutical Roundtable Solvent Selection Guide, version 2.0, 2011. [Online]

http://www.acs.org/content/dam/acsorg/greenchemistry/industriainnovation/roundtable/acs-gci-pr-solventselection-guide.pdf (accessed June 2, 2015).

(17) For the use of $\mathrm{CuCO}_{3} \cdot \mathrm{Cu}(\mathrm{OH})_{2}$ in aerobic catalysis, see: Sang, P.; Xie, Y.; Zou, J.; Zhang, Y. Adv. Synth. Catal. 2012, 354, 1873.

(18) For an overview of Cu-catalyzed reactions of aryl halides, see: a) Surry, D. S.; Buchwald, S. L. Chem. Sci. 2010, 1, 13. For examples with aryl bromides and/or chlorides, see: b) Mormino, M. G.; Fier,

P. S.; Hartwig, J. F. Org. Lett. 2014, 16, 1744. c) Maiti, D.; Buchwald, S. L. J. Org. Chem. 2010, 75, 1791. (19) a) Van Berkel, S. S.; van den Hoogenband, A.; Terpstra, J. W.; Tromp, M.; van Leeuwen, P. W. N. M.; van Strijdonck, G. P. F. Tetrahedron Lett. 2004, 45, 7659. b) Tromp, M.; van Strijdonck, G. P. F.; van Berkel, S. S.; van den Hoogenband, A.; Feiters, M. C.; de Bruin, B.; Fiddy, S. G.; van der Eerden, A. M. J.; van Bokhoven, J. A.; van Leeuwen, P. W. N. M.; Koningsberger, D. C. Organometallics 2010, 29, 3085.

(20) For Cu-catalyzed methyl transfer from alkylperoxides, see: Xia, Q.; Liu, X.; Zhang, Y.; Chen, C.; Chen, W. Org. Lett. 2013, 15, 3326.

(21) a) King, A. E.; Ryland, B. L.; Brunold, T. C.; Stahl, S. S. Organometallics 2012, 31, 7948. b) Huffman, L. M.; Casitas, A.; Font, M.; Canta, M.; Costas, M.; Ribas, X.; Stahl, S. S. Chem. Eur. J. 2011, 17, 10643. c) King, A. E.; Brunold, T. C.; Stahl, S. S. J. Am. Chem. Soc. 2009, 131, 5044.

(22) Cu-catalyzed boronic acid oxidation: Xu, J.; Wang, X.; Shao, C.; Su, D.; Cheng, G.; Hu, Y. Org. Lett. 2010, 12, 1964. Also see ref $12 \mathrm{e}$; pp 79-81.

(23) For metal-free esterification with arylboronic acids via path B, see: a) Ruso, J. S.; Rajendiran, N.; Kumaran, R. S. Tetrahedron Lett. 2014, 55, 2345.For Cu-catalyzed Fisher esterification, see: b) Ho, T.-L. Synth. Commun. 1989, 19, 2897. c) Iranpoor, N.; Firouzabadi, H.; Zolfigol, M. A. Synth. Commun. 1998, 28, 1923.

(24) Irfan, M.; Glasnov, T. N.; Kappe, C. O. Org. Lett. 2011, 13, 984.

(25) Dumur, F.; Contal, E.; Wantz, G.; Phan, T. N. T.; Bertin, D.; Gigmes, D. Chem. Eur. J. 2013, 19, 1373.

(26) Lerebours, R.; Wolf, C. J. Am. Chem. Soc. 2006, 128, 13052.

(27) Molander, G. A.; Cavalcanti, L. N. J. Org. Chem. 2011, 76, 7195.

(28) Heller, S. T.; Sarpong, R. Org. Lett. 2010, 12, 4572.

(29) Leduc, A. B.; Jamison, T. F. Org. Proc. Res. Dev. 2012, 16, 1082.

(30) Zhang, J.; Zhang, Y.; Zhang, Y.; Herndon, J. W., Tetrahedron Lett. 2003, 59, 5609.

(31) Huang, S.; Hsei, I.; Chen, C. Bioorg. Med. Chem. 2006, 14, 6106.

(32) 2j was obtained from Aldrich as a 94:6 mixture of 1-napthoic acid:2-napthoic acid, as confirmed by ${ }^{1} \mathrm{H}$ NMR. An identical ratio of methyl 1-napthoate (3j):methyl 2-napthoate was obtained from the reaction. (33) De Sarkar, S.; Grimme, S.; Studer, A. J. Am. Chem. Soc., 2010, 132, 1190. 
(34) Sechi, M.; Derudas, M.; Dallocchio, R.; Dessì, A.; Bacchi, A.; Sannia, L.; Carta, F.; Palomba, M.; Ragab, O.; Chan, C.; Shoemaker, R.; Sei, S.; Dayam, R.; Neamati, N. J. Med. Chem. 2004, 47, 5298.

(35) Black, P. J.; Edwards, M. G.; Williams, J. M. J. Eur. J. Org. Chem. 2006, 4367.

(36) Liu, X.; Hartwig, J. F J. Am. Chem. Soc. 2004, 126, 5182.

(37) Chen, C.; Zhu, S.-F.; Liu, B.; Wang, L.-X.; Zhou, Q.-L. J. Am. Chem. Soc. 2007, 129, 12616.

(38) Hesse, M.; Li, Y. Helv. Chim. Acta 2003, 86, 321.

(39) Wang, X.-R.; Chen, F. J. Chem. Res. 2010, 34, 714.

(40) Wu, F.-L.; Ross, B. P.; McGeary, R. P. Eur. J. Org. Chem. 2010, 1989.

(41) Barker, G.; O’Brien, P.; Campos, K. R. Org. Lett. 2010, 12, 4176.

(42) Iwasawa, N.; Hayakawa, S.; Funahashi, M.; Isobe, K.; Narasaka, K. Bull. Chem. Soc. Jpn. 1993, 66, 819.

(43) a) Ponticorvo, L.; Rittenberg, D. J. Am. Chem. Soc. 1954, 76, 1705. b) Kobayashi, M.; Minato, H.; Ogi, Y. Bull. Chem. Soc. Jpn. 1970, 43, 905. 